controversy as to the inheritance of acquired characters seems to render insistence on the congenital element advisable. Undoubtedly there is an inherited tendency to imitation; but from the nature of the case, the activity performed through imitation is not congenitally definite.

With Mr. Marshall's statements concerning impulse I cannót agree. If we say in common speech that "the instinct to strike is held in check," we also say that the impulse to strike is held in check. The control of our lower impulses is an important part of our moral life ; but the contention that the impulses are " prorluced by the inhibition," is open to serious criticism.

The Writer of THE Note.

\section{RECENT EXCAVATIONS AT THE PYRAMIDS OF DAHSHUR.}

FEW sources have supplied more facts for the study of anthropology than the Egyptian tombs, and the most important necropolis of Egypt is situated southeast of Cairo, close to the remains of ancient Memphis.

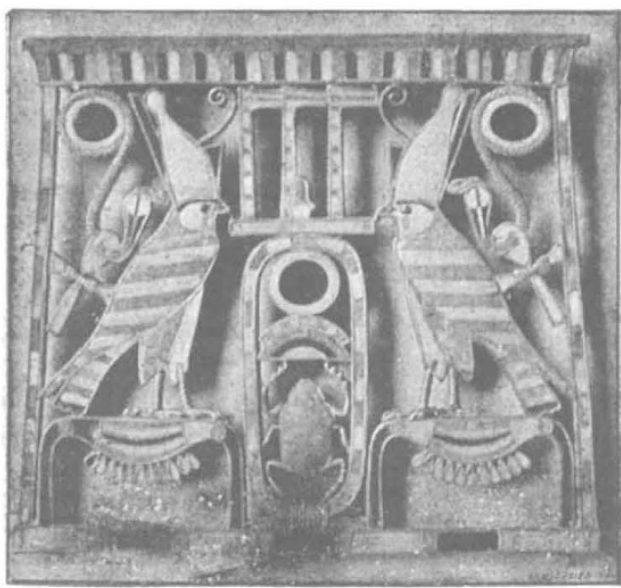

FIG. 1.-Pectoral belonging to Usertsen II. (Found March 7, I894.) layer of limestone ; each one was surrounded by a brick wall, which showed the limits of land reserved for the use of the royal family. Round this was an avenue, left out of respect to the descendants of the gods ; then came the tombs of the great pcople connected with the court. From inscriptions found, there is every reason to believe that these two pyramids belonged to Usertsen III. and Amen-em-hăt III., both of the Twelfth Dynasty. On the north side of the more northerly one are the tombs of some princesses, fotr among them more important than the rest.

These tombs have been plundered, for, owing to the Egyptian custom of burying jewels with their dead, the pyramids have ever been a favourite resort of robbers ; and thus it is that some of the tombs are in great disorder, which causes much hindrance to the scientific research now being carried on, more especially as many documents have been carried away. Still, the plunderers have not stripped them entirely, and the remaining documents and treasures have been a most important clue to finding out the dates of the pyramids and the history of the people they entomb.

This spoliation of the tombs, continued by each successive generation, was not stopped till the celebrated Mariette founded the "Service for the Conservation of Monuments in Egypt."

Amongst the most interesting and perfect pieces of jewellery found are three pectorals. They were found in the princesses'tomb, and had been hidden in the soil in order, no doubt, to deceive the plunderers.

Fig. I, the first one unearthed, has in the centre the cartouch of Usertsen II., held by two hawks, which bear the crown of Lower and Upper Egypt. The signs of the cartouch are made of cornelian, lapis-lazuli, and turquoise, set in gold; the other figures are likewise set with precious stones. The other two pectorals are similarly executed. The first (Fig. 2) represents two men, each in the act of striking with a club an Asiatic captive who they are holding by the hair. In the centre is the double cartouch of the king, and on each side the emblem of life, out of which protrude two arms holding a flabellum. Above them all is an eagle with outspread

This stretches from the village of Abou-Roash on the north to that of Mêdûm on the south, about a distance of twenty-five miles.

To the south, and at the end of the great chain of pyramids, are those of Dahshûr, of which four are of stone and two of brick. Up till I 892 the history of two of these still remained to be unravelled, but in that year a large party of excavators, headed by M. de Morgan, set out, and succeeded in opening up both these pyramids. It is to this interesting work we wish to draw attention, for it marks an important step in Egyptology, indicating some of the earliest applications of science in one direction known to us, while ancient art is at the same time illustrated. M. de Morgan has recently given an account of his explorations in Le Monde Moderne, and we are indebted to the courtesy of the Editor of that magazine for the illustrations of the finds.

The two pyramids are of brick, and covered with a NO. I 336 , VOL. 52 ]

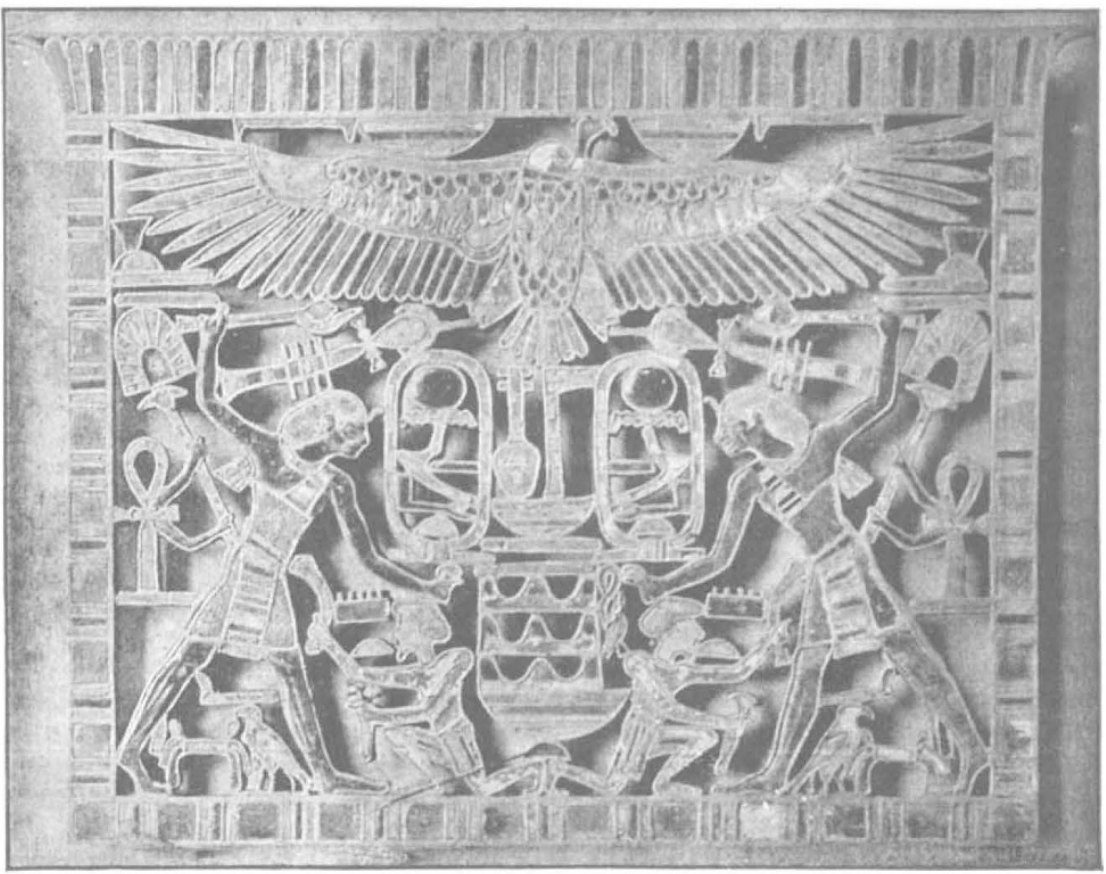

Fig. 2,-Pectoral belonging to Amen-em-hät III. (Found March 8, r894.) 
wings, having in its claws the symbols of eternal life and stability. The second one (Fig. 3) has similarly an eagle with outspread wings, and beneath it is the cartouch of Usertsen III. To the right and left is a sphinx with the head of a hawk, on which are the feathers of Ammon ; each is standing on a captive, whilst in front of each kneels an interceding Asiatic prisoner.

The workmanship of these jewels is wonderful. The perfection with which the precious stones are set, and, moreover, the delicacy and treshness of the whole, makes it hard to believe them five thousand years old. The work shows how far science dates back, and is evidence that in the case of the Egyptians, the further we look back, the higher we find their culture.

It is a curious fact that when we compare these jewels with those of a later period, we should find them far superior in workmanship; but so it is, for those of the time of the Ramessids are but an imperfect edition of the more ancient ones, not nearly so artistic, nor yet so well finished off.

When the excavations were continued, five large barges were brought to light; it was not till the work had continued some time that the royal apartments were found, so cleverly were they hidden.

The pyramid of the south is the most southerly royal monument of the Memphite necropolis. Traces are still to be found of a wall round it, and similarly situated as

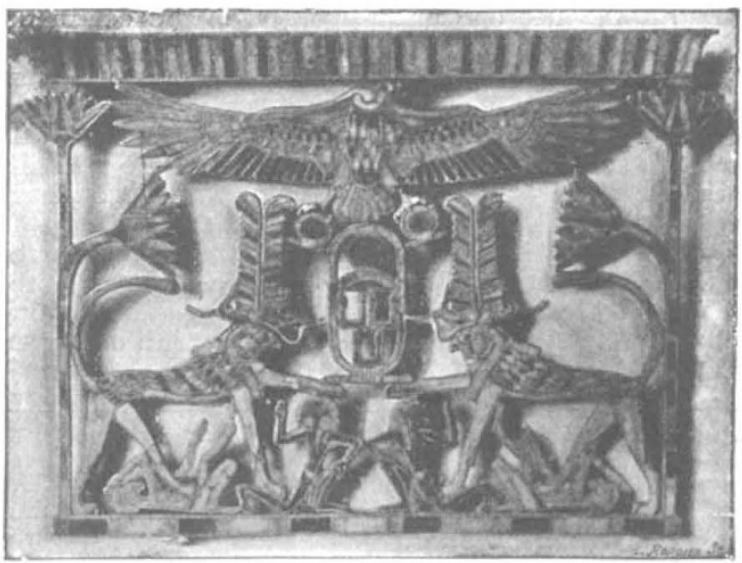

Fiti. 3.-Pectoral belonging to Usertsen III.

the princesses' tombs at the pyramid of the north; here, too, we find a gallery of twelve vaults or tombs, of which only two contain mummies, one being King Ra-Foul-Ab, and the other a princess, Queen Noub-Hotep.

Near the king's sarcophagus is a small chamber, in which were a quantity of broken vases and chests, and in a great wooden tabernacle was a statue of the double of the deceased (Fig. 4), painted grey, representing a young man of fifteen or sixteen. It is made of hard wood, almost black, and is admirably done; every muscle and rein are perfectly placed, and specialists have certified its veracity. It is a fine piece of Egyptian sculpture, of which only four good specimens have descended to us. Some savants have endeavoured to classify what has been found into certain schools, but this is scarcely advantageous till more has been collected.

The well leading to the princesses' tomb is about $\mathrm{I}_{3} \mathrm{ft}$. deep. At the bottom is a vaulted brick passage, which formerly ended in a wall. As was suspected, the wall being removed revealed a vault containing a flagstone, on which were water-jars, pieces of embalmed meat, and other offerings, also two cases, containing many things

$$
\text { NO. I } 336 \text {, VOL } 52 \text { ] }
$$

pertaining to the toilet. No inscriptions were found until the flagstone was removed, and a coffin brought to light on which were many texts relating to the name and title of the princess. As this tomb is so similar to that of King $\mathrm{Ra}-\mathrm{Fou}-\mathrm{Ab}$, and is so closely situated, it is supposed that the princess was his wife ; but nothing has been found to confirm her marriage with him.

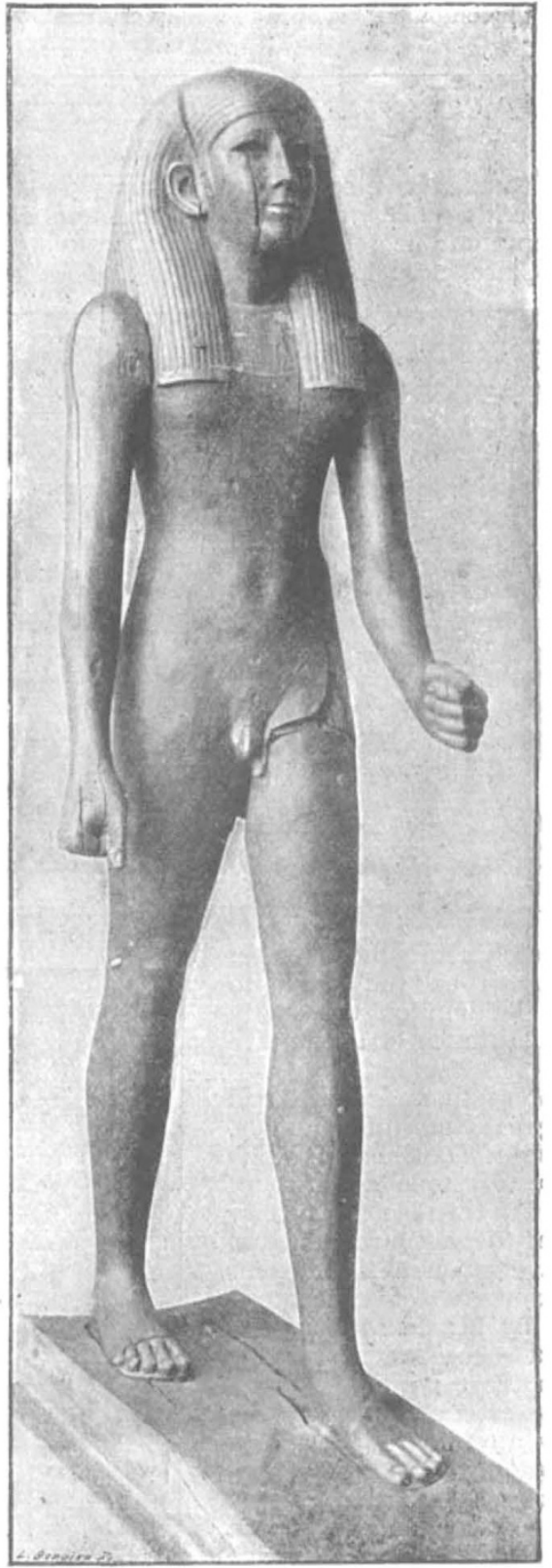

FIg. 4.--Statue of double of the King Ra-Fou-Ab. (Found April 16, 1894.)

Although a great deal has been done, it will require many years of hard work to open up all the tombs in the Dahshûr necropolis; but general interest has now been awakened, thanks to those who have been the means of making us acquainted with the preceding facts ; the results of future action will be followed by many. 